\title{
ANALISIS PROKSIMAT PADA PELET BAHAN BAKAR DARI KOTORAN BABI YANG DIKOMBINASIKAN DENGAN LIMBAH KAYU
}

\author{
I Nyoman Sukarta ${ }^{1}$, Luh Putu Ayu Lakshemini Oka ${ }^{2}$ \\ 1,2 Analis Kimia, Universitas Pendidikan Ganesha \\ Singaraja, Indonesia \\ e-mail: nyoman.sukarta@undiksha.ac.id
}

\begin{abstract}
Abstrak
Penelitian ini bertujuan untuk mengetahui karakteristik data analisis proksimat (kadar air, Ash/kadar abu, Volatile Matter (VM), Fixed Carbon (FC)). Subyek penelitian ini adalah kotoran babi dan limbah kayu sedangkan obyek penelitian ini adalah kualitas pelet variasi kombinasi kotoran babi dan limbah kayu. Pelet $(\mathrm{P})$ dibuat dengan berbagai perbandingan antara kotoran babi (KB) dan limbah kayu (LK), 10:90 ( $\left.P_{1}\right)$; 20:80 $\left(P_{2}\right)$; 30:70 ( $\left.P_{3}\right) ; 40: 60$ $\left(P_{4}\right)$; 50:50 $\left(P_{5}\right)$. Data analisis proksimat diukur dengan Thermogravimetric Analyzer (TGA) 701 merk LECO. Hasil penelitian menunjukkan bahwa : bahan baku pelet kotoran babi $(100 \%)$ memiliki kadar air $(13,20 \%)$, ash $(16,9 \%)$, VM $(50,43 \%)$ dan FC $(19,47 \%)$. Limbah kayu (100\%) memiliki kadar air $(13,26 \%)$, ash (1,19\%), VM $(84,18 \%)$ dan FC $(1,37 \%)$. Pelet dengan kadar air tertinggi terdapat pada $P_{1}$ yaitu $13,28 \%$. Pelet dengan nilai kadar ash tertinggi adalah $\mathrm{P}_{5}$ yaitu 9,19\%. Pelet dengan kadar VM tertinggi adalah $P_{1}$ yaitu $80,38 \%$. Pelet dengan kadar $F C$ tertinggi adalah $P_{5}$ yaitu $10,32 \%$.
\end{abstract}

Kata kunci: pelet bahan bakar, kotoran babi, limbah kayu, proksimat

\begin{abstract}
This study aims to determine the characteristics of proximate analysis data (moisture content, Ash / ash content, Volatile Matter (VM), Fixed Carbon (FC)). The subjects of this research are pig waste and wood waste while the object of this research is the quality of pellet variation of combination of pig manure and wood waste. Pellet $(P)$ is made with various comparisons between pig manure (KB) and wood waste (LK), 10:90 (P1); 20:80 (P2); 30:70 (P3); 40:60 (P4); 50:50 (P5). Proximate analysis data was measured by LECO Thermogravimetric Analyzer (TGA) 701. The results showed that poultry pellet $(100 \%)$ had water content $(13,20 \%)$, ash $(16,9 \%)$, VM $(50,43 \%)$ and FC $(19,47 \%)$. Wood waste $(100 \%)$ has moisture content $(13.26 \%)$, ash $(1.19 \%)$, VM $(84.18 \%)$ and FC $(1.37 \%)$. The highest water pellet was found in P1 13,28\%. The pellet with highest ash value is P5 which is $9,19 \%$. The pellet with the highest VM content is P1 which is $80,38 \%$. The pellet with the highest FC content is P5 which is $10,32 \%$.
\end{abstract}

Keywords : fuel pellet, pig manure, wood waste, proximate

\section{PENDAHULUAN}

Bahan bakar fosil merupakan bahan bakar yang paling luas dan paling sering digunakan oleh seluruh manusia di dunia ini. Penggunaan jenis bahan bakar ini semakin lama semakin tinggi, seiring dengan meningkatnya aktivitas dan jumlah penduduk bumi ini. Kenyataan itulah yang membuat dunia sekarang berada pada dua ancaman sekaligus: pemanasan global yang terus meningkat sekaligus kelangkaan sumber energi masa depan akibat berkurangnya bahan bakar fosil. Beberapa solusi pun mulai ditawarkan oleh para ilmuwan. Salah satu yang paling efektif dan ramai diperbincangkan adalah penggunaan bahan bakar alternatif. Salah satu solusi alternatif bahan bakar yang sedang giat dikembangkan saat ini adalah pelet bahan bakar (Giampietro, 2009) 
Pelet bahan bakar adalah bahan padat yang dihaluskan dan dimampatkan sehingga memungkinkan konsistensi dan efisiensi pembakarannya menjadi lebih baik dari keadaan aslinya. Pelet umumnya dibuat dari limbah kayu dan atau limbah pertanian yang umumnya memiliki nilai kalor yang tinggi dengan kandungan mineral yang rendah. Berdasarkan data International Energy Agency (IEA) Bioenergy Task 40, Global Wood Pelet Industry Market and Trade Study pada tahun 2011, saat ini produksi pelet kayu dunia mendekati 20 juta ton dengan kemampuan produksi nyaris setara. Pada tahun 2020 dengan produksi sama, diprediksi jumlah kebutuhan melambung hingga 80 juta ton (International Energy Agency, 1984). Berdasarkan siaran pers nomor: S.108/PIK-1/2010 yang dikeluarkan oleh Kepala Pusat Informasi Kehutanan menyebutkan bahwa sampai tahun 2007 Indonesia baru mampu menghasilkan pelet kayu 40.000 ton, sedangkan produksi dunia telah menembus angka 10 juta ton. Jumlah ini belum memenuhi kebutuhan dunia pada tahun 2010 yang diperkirakan mencapai 2,7 juta ton. Peluang pengembangan bahan baku dengan mengkombinasikan limbah kayu dengan bahan lain sebagai bahan baku pelet bahan bakar yang dapat dijadikan alternatif sangat terbuka luas mengingat terbatasnya sumber bahan baku limbah kayu. Beberapa penelitian yang mengkombinasikan limbah kayu dengan bahan biomassa lain sebagai bahan baku pelet bahan bakar yaitu : (Saragih, 2013)mengkombinasikan kayu sengon dengan campuran cangkang sawit sebagai pelet bahan bakar. (Sa'adah, 2014) mengkombinasikan serbuk kayu mahoni dengan limbah kelapa sawit sebagai bahan baku biopelet. Bahan baku biomassa lain yang dapat dikombinasikan dengan limbah kayu adalah kotoran ternak, karena kotoran ternak memiliki potensi dijadikan bahan bakar. Beberapa penelitian yang menyatakan potensi kotoran ternak sebagai sumber alternatif bahan bakar ditunjukkan dengan beberapa penelitian yaitu : (Haryati, 2006) Biogas limbah peternakan yang menjadi sumber energi alternatif, (Renatha, Dewi, \& Putri, 2008) membuat biogas dari limbah peternakan, (Simamora, 2009) membuat biogas pengganti bahan bakar minyak dan gas dari kotoran ternak, berdasarkan pemaparan tersebut kotoran ternak dapat dijadikan bahan baku baku alternatif pembuatan pelet bahan bakar yang dapat disubstitusikan dengan limbah kayu.

Indonesia mempunyai potensi yang baik di bidang peternakan, namun selama ini belum dikembangkan sepenuhnya. Hal ini disebabkan sebagian besar peternakan di Indonesia adalah peternakan yang bersifat tradisonal, termasuk dalam pengolahan hasil dan limbahnya belum tersentuh teknologi. Peternak biasanya menumpuk kotoran sebelum membuang atau membawanya ke sawah. Perlunya pengolahan limbah yang tepat akan dapat mengurangi dampak pencemaran terhadap lingkungan. Berdasarkan kondisi tersebut, maka perlu adanya teknologi tepat guna yang dapat memanfaatkan limbah sehingga dapat mengurangi pencemaran terhadap lingkungan sekaligus menjadi sumber energi terbarukan yang dapat mengatasi permasalahan energi. Dalam hal ini pemanfaatan kotoran babi sebagai pelet bahan bakar yang dikombinasikan dengan limbah kayu diharapkan akan dapat mengkompensasi kekurangan potensi energi dari kotoran babi melalui bentuk pelet.

Selama ini pemanfaatan kotoran babi masih sedikit. Kotoran babi baru dimanfaatkan oleh sebagian kecil masyarakat terutama untuk biogas, dan pupuk kandang. Selebihnya kotoran babi menjadi limbah dan mencemari lingkungan,

Jurnal Sains dan Teknologi | 221 
karena memiliki bau yang tidak enak, dan sering dibuang ke sungai yang menyebabkan terjadinya pencemaran sungai. Kotoran babi berpotensi menghasilkan emisi, gas metana $\left(\mathrm{CH}_{4}\right)$, hidrogen sulfida $\left(\mathrm{H}_{2} \mathrm{~S}\right)$, yang dapat dimanfaatkan sebagai bahan bakar. Disisi lain kotoran babi memiliki nilai $\mathrm{C} / \mathrm{N}$ ratio yang rendah yaitu 18 (Karki, 1984) semakin rendah kadar $\mathrm{C} / \mathrm{N}$ ratio, maka gas yang dihasilkan menjadi lebih tinggi. Selain itu produksi gas yang berpotensi dihasilkan dari kotoran babi sebesar 0,040 - 0,059 $\mathrm{kg}\left(\mathrm{m}^{3}\right)$ (Karki, 1984). Oleh karena itu, kotoran babi memiliki potensi apabila dijadikan bahan bakar alternatif dalam bentuk pelet.

Berdasarkan potensinya tersebut maka penelitian ini akan membuat pelet dengan variasi kombinasi limbah kayu dengan kotoran babi. Untuk mengetahui potensi pelet sebagai bahan bakar dilihat dari hasil analisis proksimat. Pelet yang dihasilkan dari penelitian ini diharapkan dapat dijadikan dasar untuk pengembangan energi terbarukan yang berasal dari kotoran babi dan limbah kayu.

\section{METODE}

Pelet dibuat dengan alat pencetak pelet hidrolik kapasitas 3 ton. Sebelum dicetak kotoran babi dan limbah kayu dikeringkan dan dihaluskan hingga lolos saringan 600 $\mu \mathrm{mL}$. selanjutnya dengan penambahan perekat amilum, pelet dibuat dengan berbagai variasi kombinasi campuran kotoran babi dan limbah kayu.

Pengujian yang dilakukan dalam penelitian ini adalah :

\section{Pengujian Proksimat}

Data analisis proksimatpelet yang dihasilkan dianalisis dengan menggunakan metode ASTM D7582-12 (2012). Menggunakan TGA Tipe 701 meliputi pengujian kadar air (Moisture content), kadar abu (ash content), bahan yang mudah menguap (volatile matter). Pengujian proksimat ini diuji dengan instrument Thermogravimetric Analyzer (TGA).

\section{Kadar Air (Moisture content)}

Kadar air (moisture content) dilakukan sebelum melakukan analisis yang lainnya dan ditentukan dengan metode pengeringan dengan instrumen TGA ASTM D7582-12 (2012). Dalam metode ini sampel yang telah diketahui beratnya (1 $\pm 0,1 \mathrm{~g}$ ) pada crusible tanpa tutup dikeringkan pada temperatur antara $107^{\circ} \mathrm{C}$ $\pm 3{ }^{\circ} \mathrm{C}$ selama 60 menit. Selanjutnya kadar air (moisture content) diperoleh secara otomatis oleh komputer TGA dengan persamaan 1.

$\mathrm{Mc}=\frac{\mathrm{W}-\mathrm{B}}{\mathrm{W}} \times 100$

keterangan :

Mc : kadar moisture content yang dianalisis (\%)

W : massa spesimen yang dianalisis (g)

B : massa spesimen setelah dikeringkan pada pengujian moisture $(\mathrm{g})$

\section{Bahan Mudah Menguap (Volatile matter)} Kadar volatile matter dilakukan setelah melakukan analisis kadar air. Crusible sampel pada carousel TGA ditutup dan dilakukan penimbangan ulang. Sampel dianalisis dengan dibakar dalam furnace TGA pada $950^{\circ} \mathrm{C}$ selama 7 menit (ASTM D7582-12, 2012). Persentase volatile matter pada sampel yang dianalisis diperoleh secara otomatis oleh komputer TGA yang ditentukan dengan persamaan 2 .

$\mathrm{VM}=\frac{\mathrm{B}-\mathrm{C}}{\mathrm{W}} \times 100$

keterangan :

VM : kadar volatile matter yang dianalisis $(\%)$ 
C : massa dari spesimen setelah pemanasan pada pengujian volatile matter (g)

W : massa spesimen yang dianalisis $(\mathrm{g})$

$\mathrm{B}$ : massa spesimen setelah dikeringkan pada pengujian moisture $(\mathrm{g})$

\section{Kadar Abu (Ash content)}

Kadar abu (ash) dilakukan setelah setelah melakukan analisis kadar volatile matter. Tutup crusible dibuka dan sampel dibakar dalam furnace TGA pada $750^{\circ} \mathrm{C}$ selama 1 jam (ASTM D7582-12, 2012). Persentase ash pada sampel yang dianalisis diperoleh secara otomatis oleh komputer TGA yang ditentukan dengan persamaan yang ditentukan dengan persamaan 3.

Ash $=\frac{F-G}{W} \times 100$

Keterangan :

Ash : kadar ash yang dianalisis (\%)

F : massa dari crucible dan residu abu (g)

$\mathrm{G}$ : massa dari crucible kosong ( $\mathrm{g}$ )

W: massa spesimen yang dianalisis $(\mathrm{g})$

\section{Karbon Terikat (Fixed Carbon)}

Kadar fixed carbon, ditentukan dengan persamaan 4 (ASTM D7582 - 12, 2012).

$\mathrm{FC}=100-($ kadar air + Ash + VM $) \ldots(4)$
HASIL DAN PEMBAHASAN

Tabel 1. Data Karakteristik Bahan Baku Pelet

\begin{tabular}{|c|c|c|}
\hline \multirow[b]{2}{*}{ Parameter } & \multicolumn{2}{|c|}{ Bahan Baku } \\
\hline & $\begin{array}{l}\text { Limbah } \\
\text { Kayu }\end{array}$ & $\begin{array}{l}\text { Kotoran } \\
\text { Babi }\end{array}$ \\
\hline $\begin{array}{l}\text { Kadar air } \\
(\%)\end{array}$ & 13,26 & 13,2 \\
\hline Ash (\%) & 1,19 & 16,9 \\
\hline VM (\%) & 84,18 & 50,43 \\
\hline FC (\%) & 1,37 & 19,47 \\
\hline
\end{tabular}

Tabel 2. Data Karakteristik Pelet Kotoran Babi yang Dikombinasikan Dengan Limbah Kayu Pada Berbagai Komposisi

\begin{tabular}{lllll}
\hline $\begin{array}{l}\text { Kompos } \\
\text { isi }\end{array}$ & $\begin{array}{l}\text { Kada } \\
\mathbf{r} \text { Air) } \\
(\%)\end{array}$ & $\begin{array}{l}\text { Ash } \\
(\%)\end{array}$ & $\begin{array}{l}\text { VM } \\
(\%)\end{array}$ & $\begin{array}{l}\text { FC } \\
(\%)\end{array}$ \\
\hline Pelet 1 & 13,28 & 2,95 & $\begin{array}{l}80, \\
38\end{array}$ & 3,4 \\
\hline Pelet 2 & \multirow{2}{*}{12,1} & 4,64 & $\begin{array}{l}77, \\
97\end{array}$ & $\begin{array}{l}5,2 \\
8\end{array}$ \\
\hline Pelet 3 & \multirow{2}{*}{12,17} & 4,46 & $\begin{array}{l}78, \\
28\end{array}$ & $\begin{array}{l}5,0 \\
8\end{array}$ \\
\hline Pelet 4 & \multirow{2}{*}{12,54} & \multirow{2}{*}{6,33} & $\begin{array}{l}73, \\
9\end{array}$ & $\begin{array}{l}7,2 \\
4\end{array}$ \\
\hline Pelet 5 & \multirow{2}{*}{11,03} & 9,19 & $\begin{array}{l}69, \\
46\end{array}$ & $\begin{array}{l}10 \\
32\end{array}$ \\
\hline
\end{tabular}

Dari Tabel 2. dapat dibuat grafik karakteristik pelet kombinasi kotoran babi dan limbah kayu

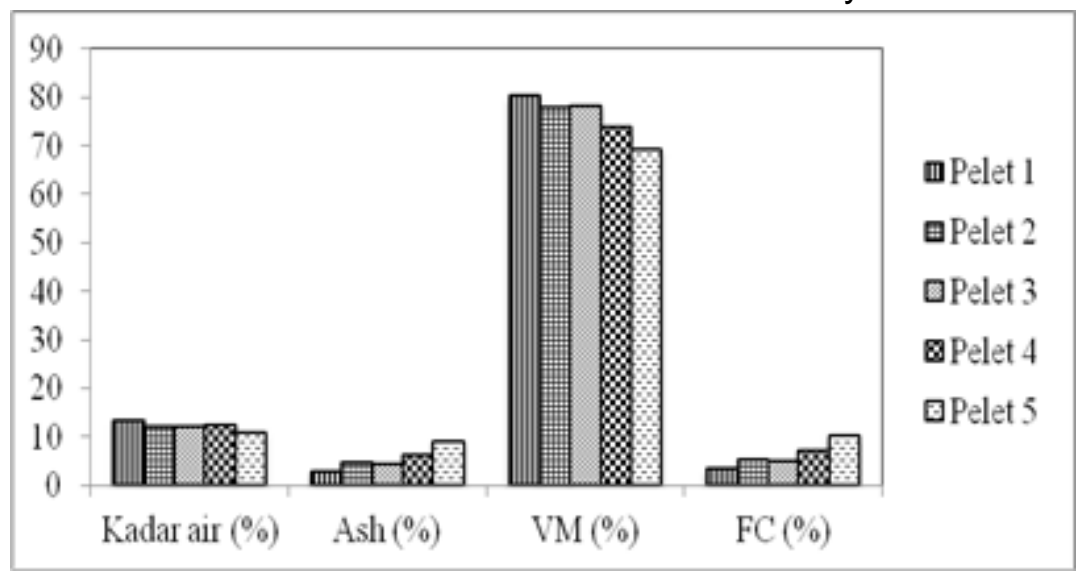

Gambar 2. Grafik Karakteristik Pelet Kotoran Babi yang dikombinasikan Dengan Limbah Kayu pada Berbagai Komposisi 


\section{Kadar Air}

Berdasarkan kadar airnya, kualitas bahan baku disajikan pada Tabel 1, kandungan air dari bahan baku limbah kayu $(13,26 \%)$ lebih tinggi dari kotoran babi $(13,20 \%)$. Hal ini disebabkan karena pori kotoran babi lebih kecil dibandingkan dengan limbah kayu, jadi dengan perlakuan waktu penjemuran dan intensitas cahaya yang sama pada proses pengeringan bahan baku menyebabkan kotoran babi memiliki kadar air yang lebih rendah.

Berdasarkan Gambar 2 terlihat bahwa kadar air tertinggi terdapat pada pelet kotoran babi dan limbah kayu dengan komposisi pertama (10:90) yaitu sebesar $13,28 \%$ dan terendah pada pelet dengan komposisi (50 : 50 ) yaitu sebesar $11,03 \%$. Kadar air dari pelet bahan bakar dengan perbandingan kombinasi komposisi kotoran babi dan limbah kayu ini konsisten dengan kadar air bahan baku kotoran babi dan limbah kayu yang diperoleh, semakin banyak komposisi limbah kayu yang ditambahkan pada komposisi pelet maka kadar air dari pelet tersebut akan semakin tinggi. Menurut (Lehtikangas, 2001)kadar air rata-rata produk pelet komersial adalah $10-12 \%$. Nilai kadar air yang diperoleh dalam penelitian ini dipengaruhi oleh lamanya pengeringan yang dilakukan. Sebagaimana halnya briket, pelet juga dibuat melalui proses pemadatan. Tekanan pemadatan yang tinggi juga dapat mempengaruhi kadar air pada pelet. Tekanan pemadatan yang tinggi dapat saling mengisi pori-pori bahan sehingga dapat mengurangi kadar air dalam pori tersebut (Sriharti dan Salim, 2011). Dalam hal ini proses pemadatan merupakan proses dewatering. Dalam penelitian ini pemadatan dilakukan dengan dongkrak hidrolik kapasitas 3 ton. Penambahan perekat tapioka pada proses pemeletan dapat meningkatkan kadar air pada pelet. Hal ini disebabkan pada proses penyiapan perekat melibatkan adanya penambahan kadar air sehingga kadar air pada pelet akan meningkat pula.

Kadar air menentukan kualitas pelet sebagai bahan bakar. Menurut (Obernberger \& Thek, 2004). Kadar air yang tinggi menurunkan nilai kalor sehingga akan mengurangi efisiensi konversi dan kinerja karena sejumlah pelet akan digunakan untuk menguapkan air tersebut. Selain itu, juga akan mencegah pembakaran lebih lanjut. Begitu juga sebaliknya. Kadar air yang rendah akan meningkatkan efisiensi dan kinerja dan melancarkan keberlanjutan pembakaran. Kadar air adalah sifat yang sangat penting dan sangat mempengaruhi karakteristik pembakaran pelet. Kadar air juga mempengaruhi perubahan suhu internal dalam bahan bakar karena penguapan endotermik, maupun karena total energi yang dibutuhkan untuk membawa hingga mencapai suhu pembakaran. Selama pembakaran, kadar air dalam pelet (bahan bakar) akan menyerap panas atau kalor untuk proses penguapan sehingga akan mengurangi nilai kalor dari pelet secara signifikan. Hal ini akan menyebabkan terjadinya kehilangan kalor atau panas untuk mendorong reaksi pembakaran sehingga suhu pembakaran menjadi lebih rendah. Akibatnya akan terjadi pembakaran yang tidak sempurna terhadap bahanbahan yang sifatnya volatil dan akan terjadi deposisi karbon yang tidak terbakar (asap) di cerobong asap atau pada bagian bawah alat memasak seperti panci yang relatif sulit untuk dibersihkan. Adanya asap yang signifikan akan dapat menghalangi aliran gas buangan dan mengurangi transfer kalor/panas ke alat memasak. Di samping itu, kadar air yang tinggi juga menyebabkan kesulitan dalam pengapian.

\section{Bahan Mudah Menguap (Volatile Matter, VM)}

Bahan-bahan yang mudah menguap (VM) adalah zat-zat yang ditemukan Jurnal Sains dan Teknologi | 224 
didalam bahan bakar seperti methana, hidrokarbon, hidrogen, karbonmonoksida, nitrogen dan gas-gas yang tidak terbakar. VM ditentukan dengan memasukkan bahan bakar dalam furnace pada temperatur $900 \pm 15^{\circ} \mathrm{C}$ selama 15 menit. Bahan-bahan yang akan menguap ketika pelet dikeringkan pada temperatur terkendali disebut kandungan bahan-bahan volatil dalam pelet. Bahan-bahan volatil tersebut menentukan kemampuan pembakaran dari suatu bahan bakar. Bahan bakar dengan kandungan VM tinggi berarti sebagian besar nilai kalor yang dimiliki akan dilepaskan sebagai uap pembakaran (Obernberger \& Thek, 2004).

Dalam penelitian ini kandungan VM pada bahan baku limbah kayu $(84,18 \%)$ lebih tinggi dari kotoran babi $(50,43 \%)$ dan pada hasil pengujian terhadap pelet kotoran babi pada berbagai komposisi seperti terlihat pada Gambar 2. pada pelet kotoran babi yang dikombinasikan dengan limbah kayu pada komposisi 10:90, 20:80, $30: 70, \quad 40: 60$, dan 50:50 berturut-turut adalah 80,$38 ; 77,97 ; 78,28 ; 73,90$; dan $69,46 \%$. Kandungan bahan mudah menguap terlihat semakin banyak komposisi kotoran babi maka kandungan VM semakin rendah. Hal ini disebabkan karena kandungan bahan mudah menguap dari kotoran babi lebih rendah dibandingkan dengan limbah kayu yang digunakan sebagai bahan utama pelet.

Kadar VM yang tinggi akan menurunkan kualitas pelet karena banyaknya VM mengakibatkan kandungan karbon semakin kecil sehingga nilai kalor yang dihasilkan semakin rendah. Kandungan VM yang tinggi pada pelet akan menimbulkan asap yang relatif lebih banyak pada saat pelet dinyalakan. Hal tersebut disebabkan oleh adanya reaksi antara karbon monoksida (CO) dan turunan alkohol (D Hendra, 2000).

\section{Kandungan Abu (Ash)}

Pada uji kandungan abu bahan baku yang ditunjukkan pada Tabel 1. limbah kayu $(1,19 \%)$ lebih rendah dari dan kotoran babi $(16,9 \%)$ Pelet kotoran babi yang dicampur dengan limbah kayu dengan berbagai komposisi seperti yang terlihat pada gambar 4.2 menunjukkan bahwa pelet pada komposisi (kotoran babi : limbah kayu ) 10:90, 20:80, 30:70, 40:60, dan 50:50 memiliki kandungan abu berturut turut yaitu : 2,$95 ; 4,64 ; 4,46 ; 6,33$; dan 9,19\%. Hal ini menunjukkan bahwa semakin banyak komposisi kotoran babi pada pelet maka kadar abunya juga semakin tinggi pula. Hal ini terjadi karena pada kotoran babi lebih banyak mengandung zat - zat yang sulit dibakar dan sulit diuapkan seperti mineral yang terikat dalam struktur karbon pada kotoran babi sehingga residu pembakaran lebih banyak akibatnya abu yang terbentuk juga semakin banyak.

Residu yang tersisa setelah pembakaran bahan bakar disebut dengan abu (ash). Semakin tinggi kandungan abu pada bahan bakar maka nilai kalor dari bahan bakar tersebut juga semakin rendah. Begitu juga sebaliknya semakin rendah kandungan abu pada bahan bakar maka nilai kalor bahan bakar tersebut juga akan semakin tinggi. Abu terbentuk dari bahanbahan mineral yang terikat dalam struktur karbon biomassa selama pembakarannya. Di samping itu, abu juga merupakan pengotor-pengotor dari bahan bakar. Kandungan abu dari bahan bakar ditentukan dengan memanaskan bahan bakar tersebut pada temperature 450$500^{\circ} \mathrm{C}$ selama kurang lebih 1 (satu) jam. Abu adalah bahan yang tidak mudah terbakar. Menurut (Obernberger \& Thek, 2004)kandungan abu yang tinggi akan menghasilkan polusi yang parah. (STUART \& KOSSON, 1994) mendifinisikan abu sebagai residu yang tersisa setelah pengapian atau pembakaran suatu zat dalam tunggu pada suhu tertentu. Ketika Jurnal Sains dan Teknologi | 225 
pelet dibakar, hanya sedikit zat yang mudah menguap (volatil) yang tertahan sebagai abu. Sementara itu, zat atau bahan-bahan volatil yang memiliki titik didih rendah akan menguap dan menjadi gas.

Selain mempengaruhi nilai kalor, kandungan abu juga diketahui menyebabkan masalah pada sistem pembakaran, terutama karena meningkatkan pencemaran dan kecendrungan untuk meningkatkan laju korosi logam dalam sistem pembakaran.

\section{Karbon Padat (Fixed Carbon, FC)}

Kandungan karbon (kandungan karbon ultimat) dari suatu bahan bakar bertanggung jawab pada kandungan energi bahan bakar. Kandungan FC bahan bakar tidak sama dengan karbon ultimat. Fixed carbon adalah karbon yang tersisa setelah bahan-bahan mudah menguap (VM) dilepaskan dari proses pembakaran. Berbeda dengan karbon ulimat yang hilang bersama hidrokarbon karena volatilitasnya. Oleh sebab itu, karbon ultimat akan menentukan jumlah karbondioksida yang dihasilkan selama pembakaran oleh suatu bahan bakar. FC digunakan sebagai estimasi jumlah arang yang akan dihasilkan dari sampel bahan bahar. Oleh sebab itu FC ditentukan dengan mengurangkan massa VM, kadar air dan ash dari massa awal suatu sampel bahan bakar atau sering dikenal dengan istilah by difference.

Pada penelitian ini diperoleh kandungan FC dalam bahan baku limbah kayu $(1,37 \%)$ lebih rendah dari kotoran babi $(19,47 \%)$ pelet kotoran babi yang dikombinasikan dengan limbah kayu dengan berbagai komposisi 10:90, 20:80, 30:70, 40:60, dan 50:50 berturut-turut adalah 3,$4 ; 5,28 ; 5,08$ ; 7,24 ; dan 10,32\%. Semakin banyak komposisi kotoran babi pada pelet, nilai FC pelet tersebut semakin besar. Hal ini disebabkan karena kandungan karbon pada kotoran babi lebih banyak dibandingkan dengan limbah kayu. Kandungan FC memang tidak termasuk sebagai parameter dalam standar PFI karena keberadaannya tidak berpengaruh secara signifikan terhadap nilai kalor bahan bakar. (Sheng \& Azevedo, 2005) melaporkan kolerasi antara nilai kalor FC sangat lemah. Namun demikian sebagaimana hal nya ash, keberadaannya dalam bahan bakar penting untuk diketahui karena dapat mempengaruhi sistem pembakaran.

\section{SIMPULAN DAN SARAN}

\section{Simpulan}

Hasil penelitian ini menunjukkan bahwa

1.Kotoran babi yang digunakan dalam penelitian ini memiliki kadar air (13,20\%), ash (16,9\%), VM $(50,43 \%)$ dan FC $(19,47 \%)$. Limbah kayu memiliki kadar air $(13,26 \%)$ dan VM $(84,18 \%)$ lebih tinggi, serta ash (1,19\%) dan FC (1,37\%) lebih rendah dibandingkan kotoran babi. Potensi energi limbah kayu sebagai bahan baku bahan bakar padat lebih baik dibandingkan kotoran babi.

2.Pelet dengan kadar air tertinggi terdapat pada $P_{1}$ yaitu $13,28 \%$, sedangkan terendah adalah $P_{5}$ yaitu $11,03 \%$. Pelet dengan kandungan Ash tertinggi adalah $P_{5}$ yaitu $9,19 \%$, sedangkan terendah adalah $\mathrm{P}_{1}$ yaitu $2,95 \%$. Pelet dengan VM tertinggi adalah $P_{1}$ yaitu $80,38 \%$ sedangkan terendah adalah $\mathrm{P}_{5}$ yaitu $69,46 \%$. Pelet dengan FC tertinggi adalah $P_{5}$ yaitu $10,32 \%$ sedangkan terendah adalah $P_{1}$ yaitu $3,4 \%$. Potensi energi pelet dengan kombinasi komposisi kotoran babi dan limbah kayu yang berbeda dipengaruhi oleh jumlah penambahan kotoran babi yang ditambahkan.

\section{Saran}

Saran yang dapat diberikan berdasarkan hasil penelitian yang telah dilakukan adalah perlu dilakukan Jurnal Sains dan Teknologi | 226 
penambahan variasi komposisi pelet dari kotoran babi dan limbah kayu agar diperoleh variasi komposisi yang memiliki potensi energi yang optimum

\section{DAFTAR PUSTAKA}

D Hendra, G. P. (2000). Penyempurnaan Teknologi Pengolahan Arang. Laporan Hasil Penelitian. Pusat Penelitian Hasil Hutan, Badan Penelitian Dan Pengembangan Kehutanan, Bogor.(Belum Diterbitkan).

Giampietro, M. (2009). The Biofuel Delusion: The Fallacy of Large Scale Agro-Biofuels Production. London,UK: Earthscan.

Haryati, T. (2006). Biogas: limbah peternakan yang menjadi sumber energi alternatif. Wartazoa, 16(3), 160-169.

International Energy Agency. (1984). Updated guidebook on biogas development. United Nations, New York, USA. Retrieved from http://www.ircwash.org/sites/default/file s/352.1-84UP-3638.pdf

Karki, A. B. and D. K. (1984). Biogas Fieldbook. Kathmandu, Nepal: Sahayogi Press.

Lehtikangas, P. (2001). Quality properties of pelletised sawdust, logging residues and bark. Biomass and Bioenergy, 20(5), 351-360. https://doi.org/10.1016/S09619534(00)00092-1

Obernberger, I., \& Thek, G. (2004). Physical characterisation and chemical composition of densified biomass fuels with regard to their combustion behaviour. Biomass and Bioenergy,
$27(6)$ 653-669.

https://doi.org/10.1016/j.biombioe.2003 .07 .006

Renatha, R., Dewi, R., \& Putri, A. (2008). PEMBUATAN BIOGAS dari LIMBAH PETERNAKAN, (24), 6-7.

Sa'adah, W. A. (2014). Pemanfaatan Limbah Kelapa Sawit (Elaeis guineensis Jacq.) dan Serbuk Kayu Mahoni sebahai Bahan Baku Biopelet.

Saragih, A. (2013). Karakteristik biopelet dari campuran cangkang sawit dan kayu sengon sebagai bahan bakar alternatif terbarukan ardy edo saragih.

Sheng, C., \& Azevedo, J. L. T. (2005). Estimating the higher heating value of biomass fuels from basic analysis data. Biomass and Bioenergy, 28(5), 499-507.

https://doi.org/10.1016/j.biombioe.2004 .11 .008

Simamora, S. (2009). Membuat Biogas; Pengganti Bahan Bakar Minyak \& Gas dari Kotoran Ternak. Agro Media.

Sriharti dan Salim, T. (2011). Pengaruh Komposisi Bahan Terhadap Karakterisasi Briket Limbah Biji Jarak Pagar (Jatropha Curcas Linn). Teknologi Indonesia, 34, 40-48.

STUART, B. E. N. J., \& KOSSON, D. S. (1994). Characterization of Municipal Waste Combustion Air Pollution Control Residues as a Function of Particle Size. Combustion Science and Technology, 101(1-6), 527-548. https://doi.org/10.1080/001022094089 51891 